\title{
A Convenient Samarium-Promoted Synthesis of Aliphatic (E)- Nitroalkenes under Mild Conditions
}

\author{
José M. Concellón,* Humberto Rodríguez-Solla and Carmen Concellón \\ Departamento de Química Orgánica e Inorgánica, Facultad de \\ Química, Universidad de Oviedo, Julián Clavería, 8, 33071 Oviedo, \\ Spain. \\ jmcg@uniovi.es
}

\section{Supporting Information}

General and General Procedure

1-Bromo-1-nitrododec-11-en-2-ol (2f)

(Z)-1-Bromo-1-nitroundec-7-en-2-ol (2g)

(E)-1-Nitronon-1-ene (3a)

S5

(E)-4-Methyl-1-nitropent-1-ene (3b).

S6

(E)-3-Methyl-1-nitropent-1-ene (3c).

S7

(E)-3-Phenyl-1-nitroprop-1-ene (3e).

S8

(E)-1-Nitrododeca-1,11-diene (3f).

S9

(1E,7Z)-1-nitroundeca-1,7-diene (3g).

$\mathrm{S} 10$ 


\section{General}

Reactions requiring an inert atmosphere were conducted under dry nitrogen, and the glassware was oven dried (120

$\left.{ }^{\circ} \mathrm{C}\right)$. THF was distilled from sodium/benzophenone ketyl immediately prior to use. All reagents were purchased in the higher quality available and were used without further purification. Flash column chromatography was carried out on silica gel 230-400 mesh. Compounds were visualized on analytical thin layer chromatograms (TLC) by UV light (254 nm). ${ }^{1} \mathrm{H}$ NMR spectra were recorded at 200,300 or $400 \mathrm{MHz} .{ }^{13} \mathrm{C}$ NMR spectra and DEPT experiments were determined at 50 or $75 \mathrm{MHz}$. Chemical shifts are given in ppm relative to tetramethylsilane (TMS), which is used as an internal standard, and coupling constants $(J)$ are reported in Hz. The stereoisomeric ratios were determined using ${ }^{1} \mathrm{H}$ NMR analysis and GC-MS of crude products. GC-MS and HRMS were measured at $70 \mathrm{eV}$ or using FAB conditions. When HRMS could not be measured on molecular ion the HRMS of a significant fragment is given. Only the most important IR absorptions $\left(\mathrm{cm}^{-1}\right)$ and the molecular ions and/or base peaks in MS are given.

General Procedure for the Synthesis of nitroalkenes 3 from aldehydes 1: $\mathrm{NaI}(0.12 \mathrm{mmol}, 0.15$ equiv. $)$ was added to a stirred solution of bromonitromethane $(0.8 \mathrm{mmol}, 1$ equiv.) and the corresponding aldehyde 1 ( $0.8 \mathrm{mmol}, 1$ equiv.) in THF $(10 \mathrm{~mL})$. After stirring the reaction at room temperature for two hours it was quenched by addition of aqueous $\mathrm{HCl}(10 \mathrm{~mL}, 0.1 \mathrm{M})$ before the organic material was extracted with dichloromethane. The combined extracts were washed with an aqueous saturated solution of $\mathrm{Na}_{2} \mathrm{~S}_{2} \mathrm{O}_{3}$ and then dried over $\mathrm{Na}_{2} \mathrm{SO}_{4}$. Finally the solvent was removed under reduced pressure affording pure compound 2. A solution of $\mathrm{SmI}_{2}$ (2.0 mmol, 2.5 equiv.) in THF (20 $\mathrm{mL}$ ) was then added to a stirred solution of corresponding crude product 2 in THF ( $5 \mathrm{~mL})$. After stirring the reaction at room temperature for two hours it was quenched by addition of aqueous $\mathrm{HCl}(10 \mathrm{~mL}, 0.1 \mathrm{M})$ before the organic material was extracted with dichloromethane. The combined extracts were washed with an aqueous saturated solution of $\mathrm{Na}_{2} \mathrm{~S}_{2} \mathrm{O}_{3}$ and then dried over $\mathrm{Na}_{2} \mathrm{SO}_{4}$ and the solvent was removed under reduced pressure affording crude products 3 .

Compounds 2a-e were fully characterized in Concellón, J. M.; Rodríguez-Solla, H.; Concellón, C.; García-Granda, S.; Díaz, M. R. Org. Lett. 2006, 8, 5979-5982.

Compound 3d was fully characterized in Denmark, S. E.; Marcin, L. R. J. Org. Chem. 1993, 58, 3850-3856.

Although other compounds $\mathbf{3}$ were previously synthesized, no fully characterization was however given: 3a, Sakakibara, T.; Takai, I.; Ohara, E.; Sudoh, R. J. Chem. Soc., Chem. Commun. 1981, 6, 261-262; 3c, Kantam, M. L.; Sreekanth, P. Catal. Lett. 1999, 57, 227-231; and 3e, Myers, A. G.; Barbay, J. K.; Zhong, B. J. Am. Chem. Soc. 2001, 123, 7207-7219; Ochiai, M.; Fujita, E.; Arimoto, M.; Yamaguchi, H. Chem. Pharm. Bull. 1984, 32, 5027-5030. For this reason, the fully characterization of these compounds is also given in the published paper. 


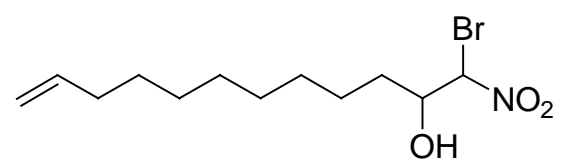

$2 f$
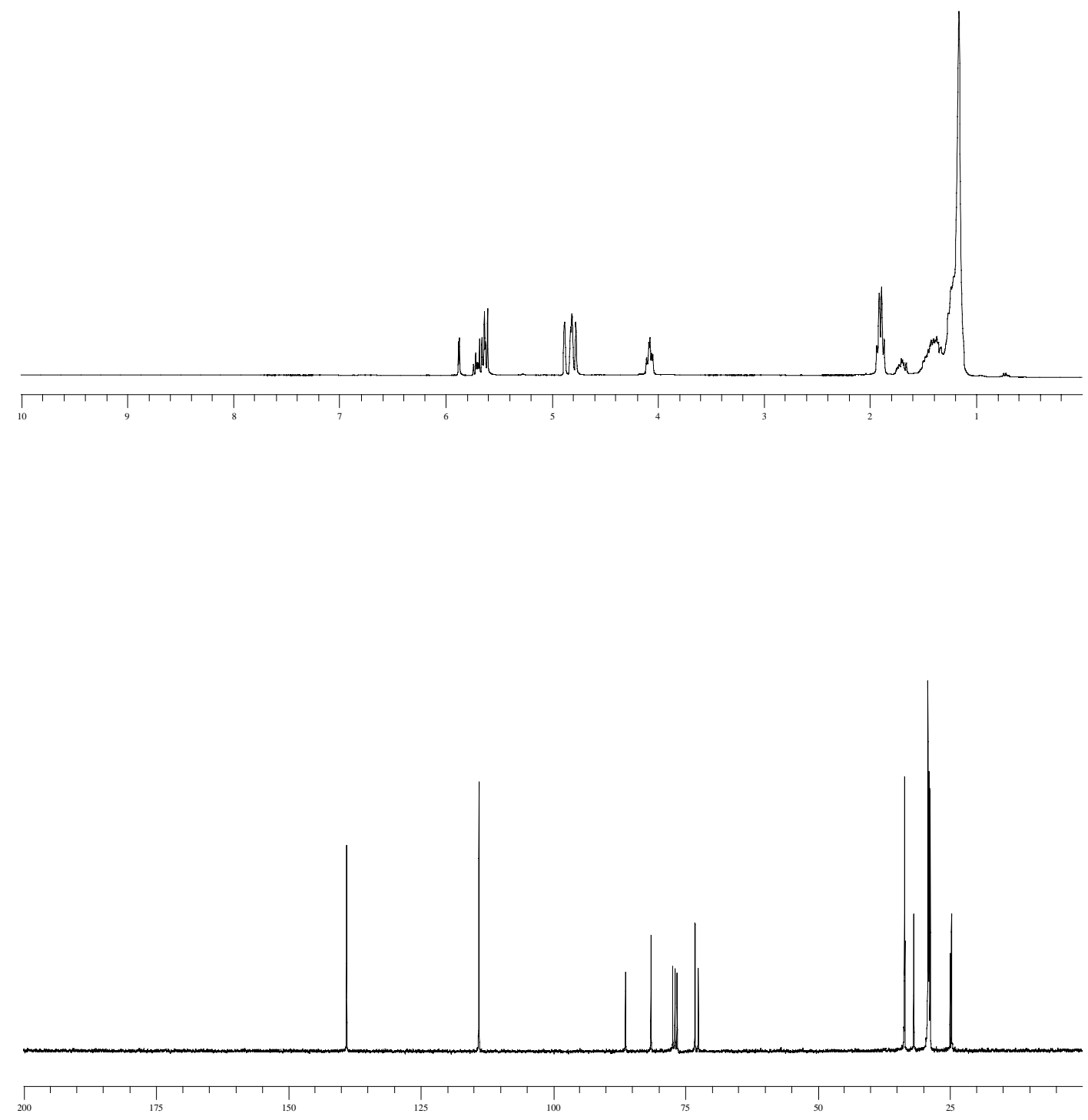


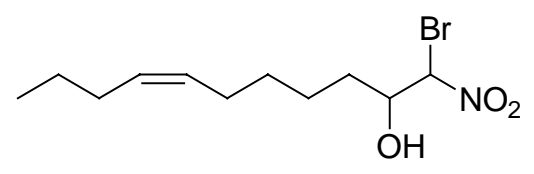

$2 \mathrm{~g}$
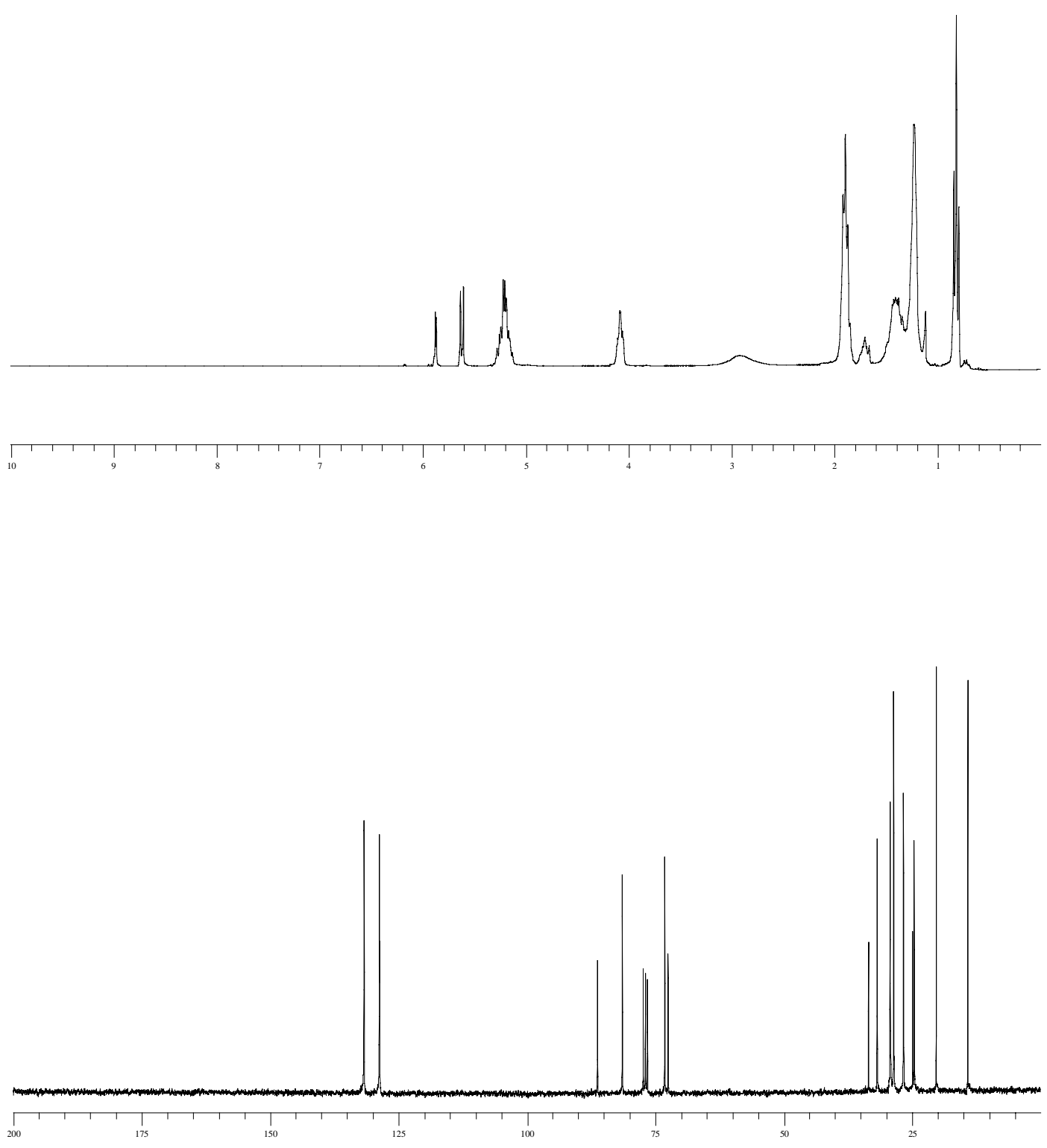

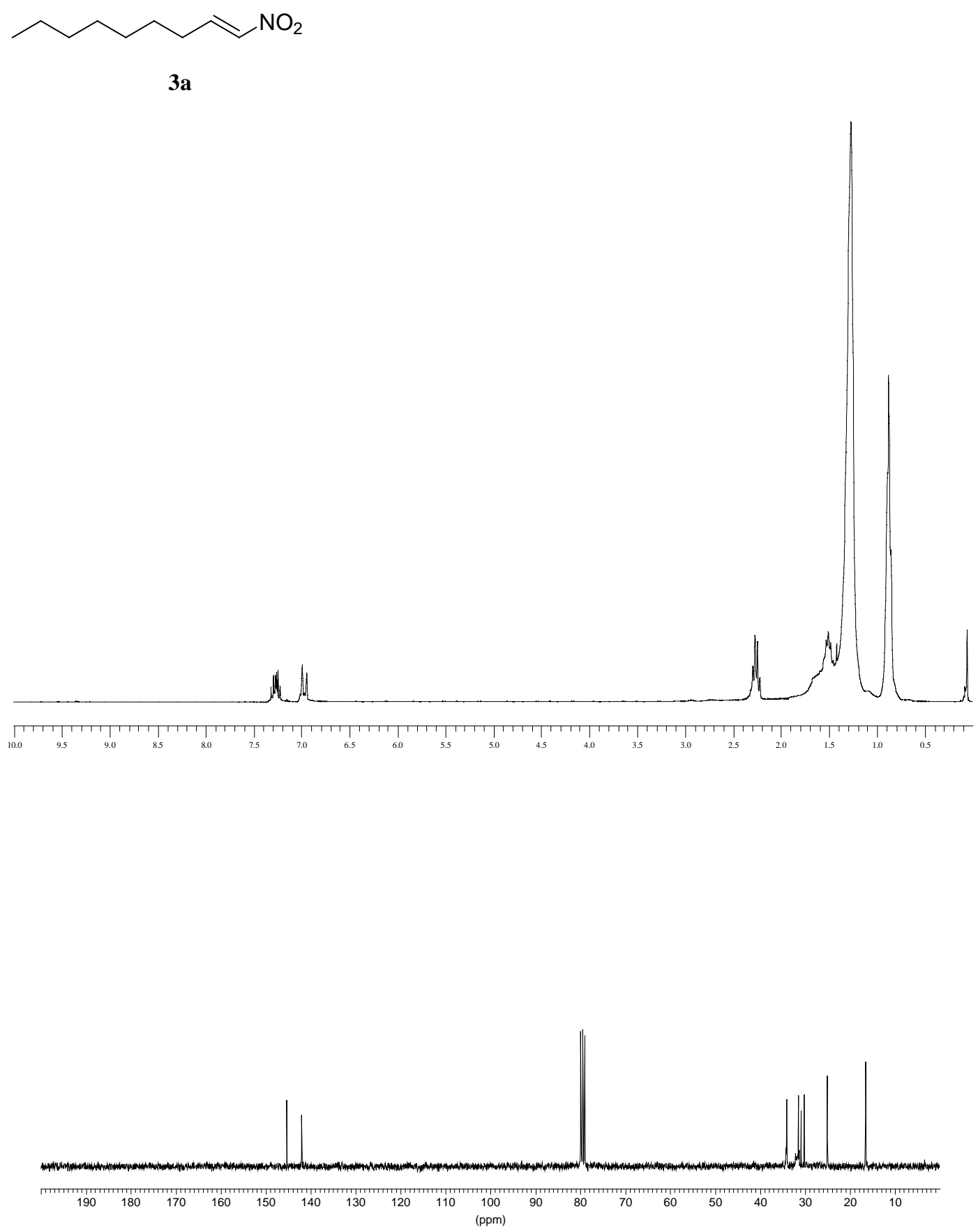


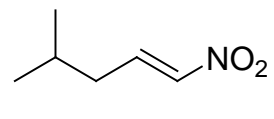

3b
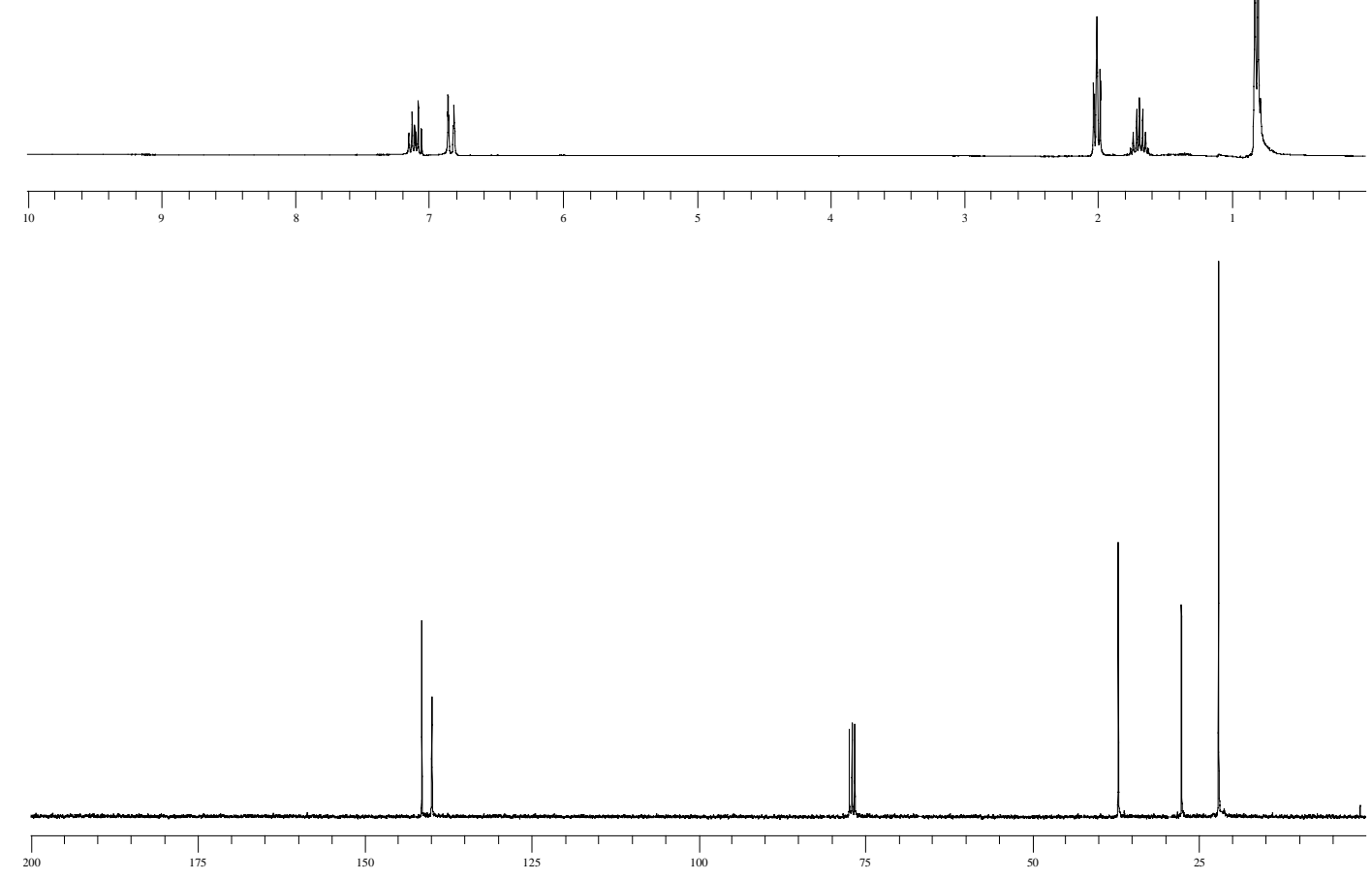


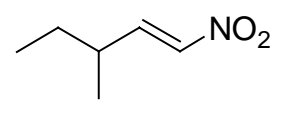

3c
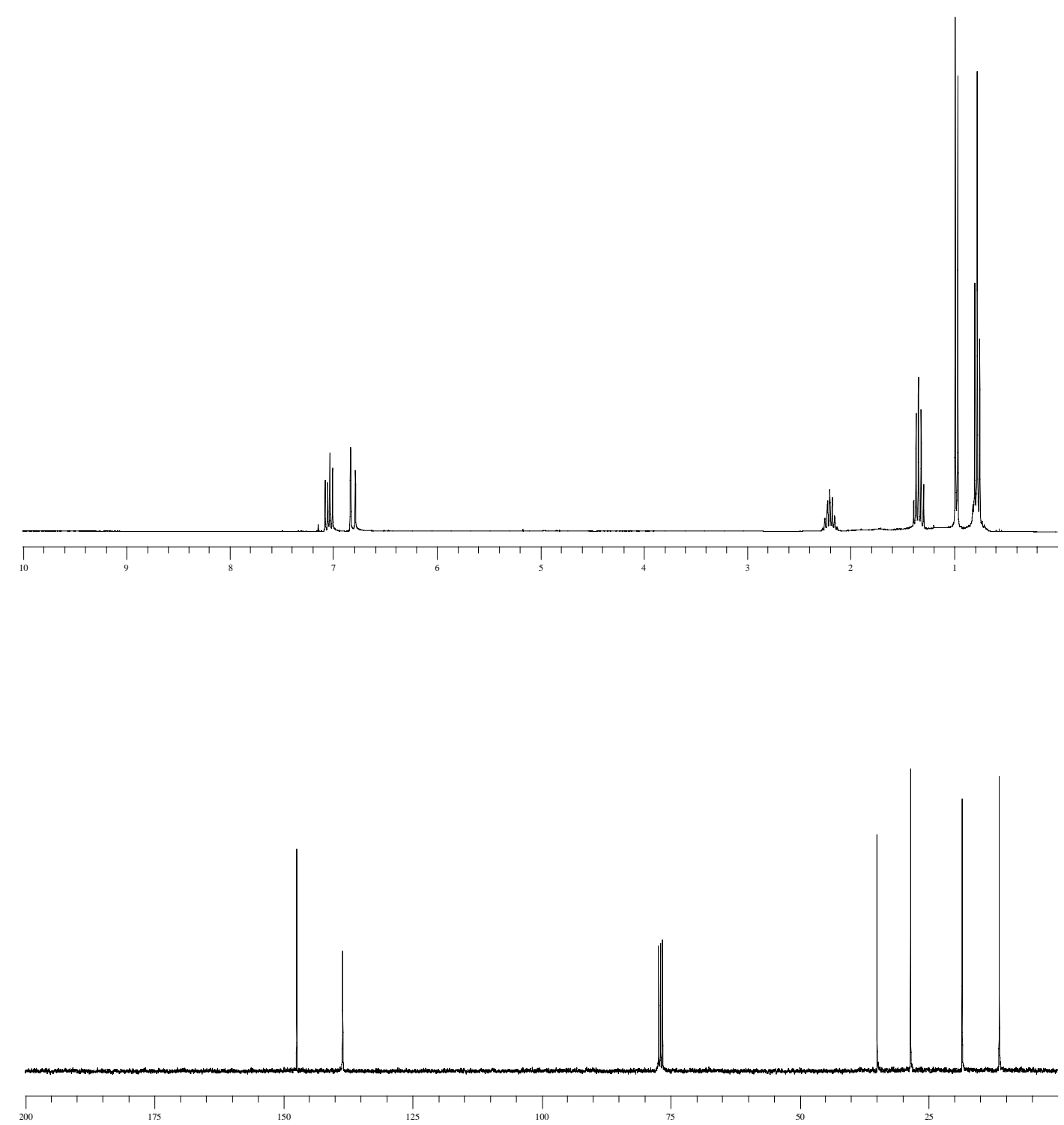

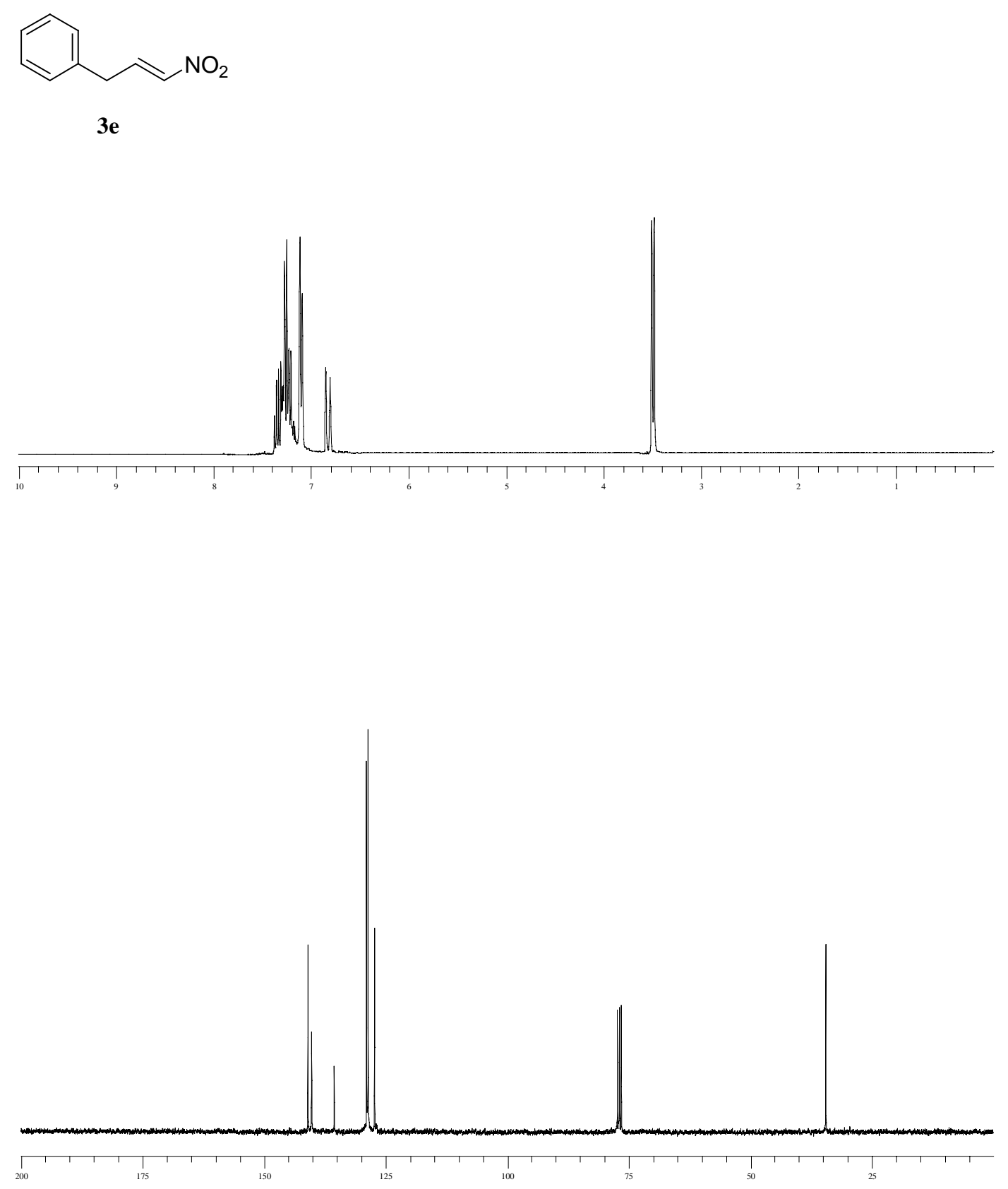

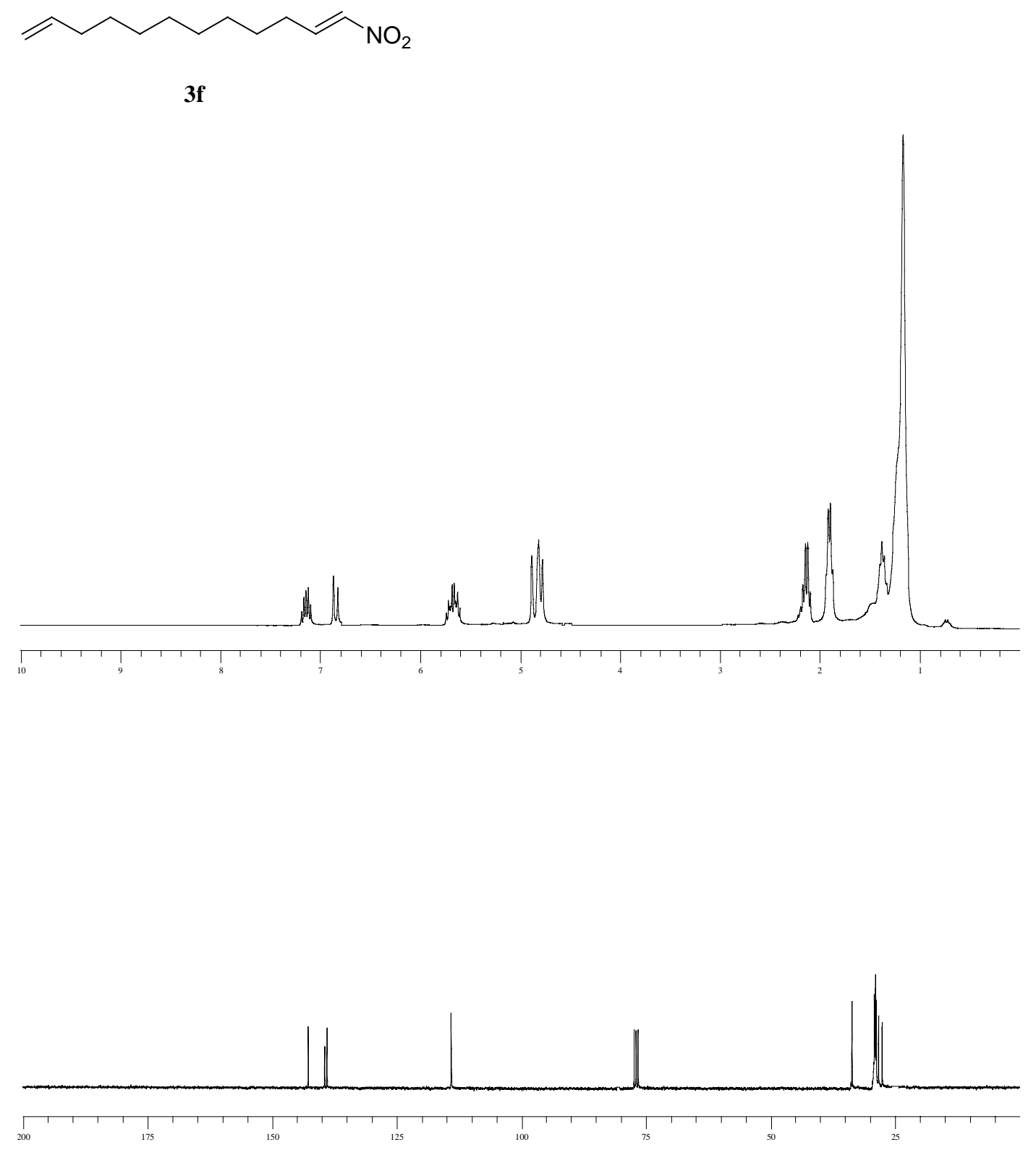


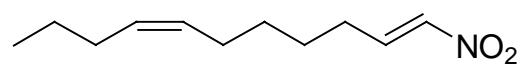

$3 g$
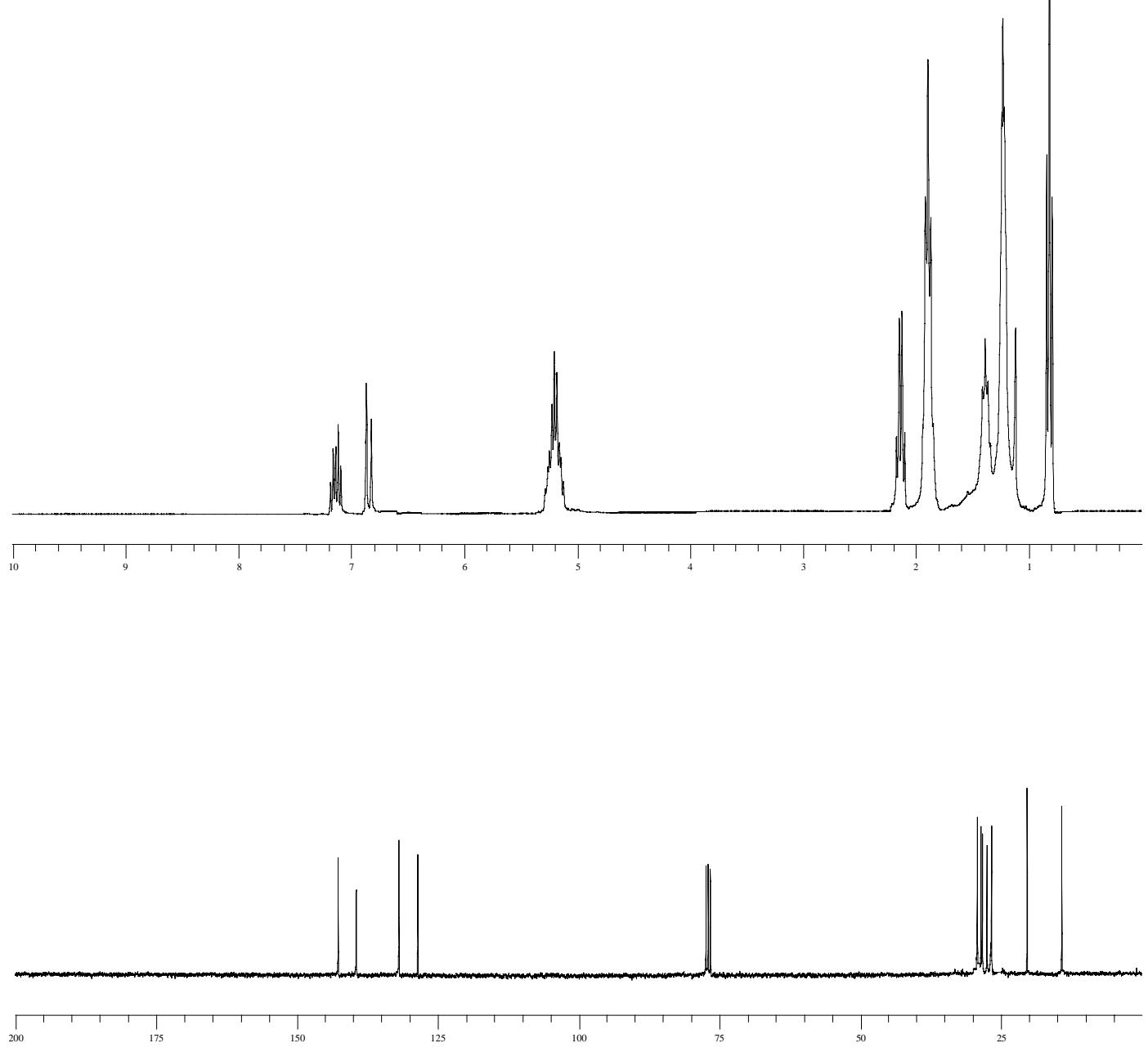